\title{
A PEDAGOGIA DAS COMPETÊNCIAS: AUTONOMIA OU ADAPTAÇĀO?*
}

Celso JoÃo Ferrettit ${ }^{* *}$

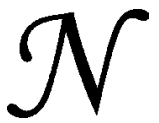

ão é novidade para ninguém que a ciência transformou-se rapidamente em força produtiva no contexto da produção capitalista, principalmente a partir da segunda metade do século XIX, situação que se intensificou no decorrer do século XX e que, ao final deste, atinge um plano elevado e complexo, de tal forma que, hoje, com a automação e a utilização crescente da informática, o conhecimento tornou-se matéria vital para o processo de acumulação capitalista. Isto traz conseqüências importantes não apenas para a produção em si, mas para toda a organização social.

$\mathrm{O}$ interesse crescente do capital pelo conhecimento produzido e pela produção científica o faz investir cada vez mais em setores que antes lhe eram periféricos, como o da educação, não apenas porque ela própria tende a se transformar em mercadoria, mas também porque a competição exige a produção de conhecimento científico cada vez mais sofisticado, além de que a introdução de inovaçôes tecnológicas na base física, tanto quanto na organização das empresas, acaba criando novas demandas em relação aos trabalhadores. $\mathrm{O}$ conhecimento em geral e o científico em particular tornam-se alvo de disputas acirradas e de investimentos vultuosos, bem como de investidas ideológicas que pretendem transformá-los na chave de sucessos pessoais e empresariais.

No campo da ciência, as relaçōes entre o Estado e o setor privado são marcadas ora pela luta com vistas à propriedade intelectual do

\footnotetext{
* Resenha do livro de Marise Nogueira Ramos (São Paulo: Cortez, 2001).

** Pesquisador sênior da Fundação Carlos Chagas e professor do Programa de Estudos Pós-Graduados em Educação: História, Política, Sociedade da Puc/sp. E-mail: cferretti@fcc.org.br
} 
conhecimento, ora pelas articulações entre ambos para a produção de conhecimentos que lhes são mutuamente vantajosos. Tais articulações têm implicações quanto à definição de quem produz o quê em termos de ciência básica e ciência aplicada, nos planos nacional e internacional, e quem detém ou pode deter direitos de propriedade, distribuição e uso do conhecimento produzido.

$\mathrm{Na}$ trama de tais articulações, as instituições de ensino são bastante afetadas, pois o papel social que lhes é atribuído passa a ser muito marcado por essas mesmas articulações, que ora fazem com que o Estado carreie recursos vultuosos para determinados setores do ensino, ora que lhes retire tais recursos, por força das opções que tem de fazer com relação a que tipo de conhecimento produzir e que tipo de ensino valorizar.

Sob o argumento principal de que as mudanças que estão ocorrendo na esfera do trabalho desde os anos 60/70 do século XX, mas que se fizeram mais patentes no decorrer dos anos 80 e, principalmente, dos anos 90, demandariam um novo tipo de trabalhador, mais ilustrado, mais informado, possuidor de níveis de escolaridade mais altos, desencadeia-se, durante a última década daquele século, um intenso movimento de reformas educacionais que viriam a atingir todos os níveis da educação nacional.

Das mais diversas formas e por diversos meios esses elementos se fizeram presentes em muitas políticas internacionais e nacionais. No primeiro caso, principalmente por intermédio da ação sistemática de organismos multilaterais. No segundo, pela ação não apenas do Estado, mas de diferentes grupos sociais.

Sob tais circunstâncias, a educação tem sido, de um lado, exaltada pelas contribuições que poderia oferecer para a constituição de sociedades mais ricas, mais desenvolvidas, mais igualitárias e mais democráticas e, de outro, especialmente em países como o nosso, profundamente questionada, por não estar em condições de garantir à população em geral o acesso aos bens culturais, sociais e econômicos que poderiam garantir-lhe os benefícios decorrentes de sua pertença a uma sociedade afluente.

Em virtude deste último argumento, as políticas educacionais recentemente traçadas pelo Estado brasileiro, em articulação com diferentes setores sociais, têm afirmado não apenas a intenção de elevar o nível de qualidade da educação pública, mas de fazê-lo de modo que esta cumpra o papel que lhe caberia, segundo tais políticas, 
na promoção do desenvolvimento nacional. Acabaram, assim, por estabelecer uma relação estreita e mais ou menos direta entre educação e trabalho, com base no pressuposto, anteriormente referido, das novas demandas deste último à sociedade.

Como elemento central desses discursos e ações justificadoras, desponta o denominado "modelo de competência", que se transforma em pedra de toque das reformas educacionais brasileiras. São vários os argumentos brandidos em torno de sua adoção, mas os principais dizem respeito à "necessidade", posta pelas transformaçôes em diversas esferas, mas especialmente na econômica, de as sociedades em geral, mas em particular as "emergentes", buscarem a constituição de um novo sujeito social, no plano coletivo, tanto quanto no individual, capaz não só de conviver com tais transformações, mas, principalmente, tirar delas o melhor partido, tendo em vista o bem estar de países e pessoas.

O livro de Marise Nogueira Ramos, que é um desdobramento de sua tese de doutorado na Universidade Federal Fluminense (UFF), remete ao exame crítico, de caráter teórico e político, do conceito de competência e da constituição do que denomina de "pedagogia das competências”, cuja origem, na França, remonta ao ensino técnico. Tal pedagogia é entendida pela autora como aquela na qual,

em vez de se partir de um corpo de conteúdos disciplinares existentes, com base no qual se efetuam escolhas para cobrir os conhecimentos considerados mais importantes, parte-se de situaçôes concretas, recorrendo-se às disciplinas na medida das necessidades requeridas por essas situações. (P. 221)

tornando-a compatível com o que, segundo os discursos correntes, é demandado dos "novos" trabalhadores das empresas flexibilizadas. Diante desse tipo de proposta, a autora faz uma indagação que, além de servir de subtítulo ao livro, percorre-o de alto a baixo: tal pedagogia conduz à autonomização dos sujeitos a ela expostos ou à sua mera adaptação às mudanças no trabalho e na vida social?

Para dar conta dessa empreitada, Ramos organiza seu texto em cinco capítulos. No primeiro, faz uma retomada de muito bom nível da literatura que discute a qualificação e a competência, pois uma de suas teses centrais é a de que as transformações atuais no capitalismo produzem um deslocamento conceitual do conceito de qualificação para o de competência. Todo o restante do texto é organizado em torno de três grandes eixos: o sócio-empírico, o teórico-filosófico e o 
utópico, por meio dos quais se realiza o exame aprofundado do modelo de competência e seus desdobramentos para o campo do trabalho e da educação. Os capítulos 2 e 3 estão articulados em torno do primeiro eixo. No capítulo 2 a competência é examinada em sua dimensão teórica; depois se analisa sua incorporação pelas reformas brasileiras do ensino médio e do ensino técnico (capítulo 3). Em torno do segundo eixo organizam-se os capítulos 4 e 5 . Neles a competência é analisada como ordenadora, de um lado, das relaçóes de trabalho (capítulo 4) e, de outro, das relaçóes educativas (capítulo 5). Finalmente, nas conclusões, que se identificam com o eixo utópico, a autora discute a noção do modelo de competências, considerando os limites deste para a formação humana, propondo sua ressignificação, nos marcos da qualificação como relação social, tendo em vista os interesses dos trabalhadores.

Muito bem estruturado, o livro conduz o leitor paulatinamente ao domínio do conceito de competência, bem como à compreensão de como é utilizado tanto pelo setor empresarial quanto pelo educacional. Não obstante a qualidade do texto como um todo, considero necessário chamar a atenção para algumas de suas partes. Destaco, assim, o capítulo inicial, pois ele se debruça sobre uma temática atual em torno da qual se trava uma polêmica inconclusa e complexa, mesmo no campo da Sociologia do Trabalho, qual seja, o debate teórico/prático sobre a qualificação e sua possível substituição pelo conceito de competência.

Considero que aqui a autora define o terreno teórico no qual se moverá o texto, no que diz respeito a esse debate. Sua importância decorre não apenas da retomada do debate, mas da recuperação que faz das discussões históricas sobre a qualificação profissional e da articulação que estabelece entre as postulaçôes de Naville (1956) sobre a qualificação e as de Schwartz (1995) a respeito desta e das competências, o que lhe permite postular, como faz Tartuce (2002), que, para além da oposição entre ambos os conceitos, é necessário recuperar a tensão dialética entre eles, tensão que se expressa na concepção de que, apesar da ênfase posta no desenvolvimento das competências, estas só ganham sentido se entendidas como parte do conceito mais amplo de qualificação como construção e relação social, ou, em outros termos, de acordo com a perspectiva relativista proposta por Naville.

Este movimento permite à autora encarar a qualificação não da perspectiva funcionalista proposta pelo Capital, segundo a qual a 
subjetividade é travestida em conjuntos de atitudes e comportamentos sociais que passam a constituir, junto com atributos técnicos e cognitivos, o novo rol de "qualificações profissionais" demandado pela empresa "moderna". Ao contrário, como sugere Machado (1996), é necessário lançar mão de uma qualificação profissional que se ponha como mediadora na construção social de identidades individuais e coletivas e que, nesse processo, adquira legitimidade. Este é precisamente o caso da qualificação entendida como construção e relação social. Ela implica examinar e relacionar organicamente, em cada momento histórico, os vários elementos que constituem a situação de trabalho, como sugere Villavicencio (1992) e detalha Machado (as formas de organização social do trabalho, da construção de redes de intercâmbio e circulação de saberes, da capacidade dos indivíduos de construir linguagens, formas de comportamento, relações de negociação, de aliança e de enfrentamento), bem como os elementos que contribuem e contribuíram, do ponto de vista das aprendizagens formais e dos processos de socialização, internos e externos às situações de trabalho, para configurar as qualificações da força de trabalho, individual e coletivamente.

Dois outros capítulos, o quarto e o quinto, estruturados de uma perspectiva teórico-filosófica, parecem-me também merecedores de uma atenção mais detida. Neles, Ramos se volta para a reflexão a respeito de como a materialidade que pouco a pouco vai adquirindo o conceito de competência entre nós, seja no setor produtivo, seja no educacional, interfere nas concepções atuais sobre as relações entre o trabalho e a educação. Este parece ser o momento do texto em que a autora, tendo abordado anteriormente o deslocamento conceitual do conceito de qualificação ao de competência, opera suas análises sob a convicção de que, independentemente das indefinições e disputas examinadas no primeiro capítulo, esta última (a competência) se póe, no caso brasileiro, como ordenadora das relações de trabalho e das relações no campo da educação. Pode-se aceitar essa postulação em tese, pois tanto no campo do trabalho, como no educativo, percebemse ações e movimentos nessa direção. No entanto, é necessário considerar esse processo com cautela, pois a materialidade do campo do trabalho, assim como da educação, sugere que a incorporação da competência como elemento regulador das relações sociais em ambos os campos é ainda incipiente e contraditória, devendo ser objeto de investigaçôes que o texto suscita, mas que não se propõe aprofundar, tais como as que se referem às formas pelas quais empresas e 
instituições educacionais estão operando concretamente com tal conceito.

No capítulo 5 e em boa parte de suas conclusões, após as minuciosas análises precedentes, que lhe permitiram postular que a teoria funcionalista predomina nos estudos e ações que procuram identificar e promover o desenvolvimento de competências, entendidas estas como fator de produção, a autora examina no que consiste a "pedagogia das competências", na sua dimensão psicológica, assim como na socioeconômica. Embora mostrando que as abordagens em relação à primeira dimensão não privilegiam necessariamente apenas a concepção mais estreita de competência, que a remete ao desempenho frente a demandas objetivas, Ramos salienta que esta última é a visão predominante. Quanto à segunda dimensão, ressalta que a tendência que se apresenta mais forte na "pedagogia das competências" é a que enfatiza o desenvolvimento de sujeitos que privilegiam seus projetos pessoais de profissionalização em detrimento de uma outra perspectiva, em que a profissionalidade resulta de construçôes e compromissos coletivos dos trabalhadores.

Indicadas essas tendências mais gerais da "pedagogia das competências", Ramos examina as implicações curriculares que ela carrega. Conforme salienta,

o ponto convergente da discussão curricular que toma o desenvolvimento de competências como referência, é a crítica à compartimentação disciplinar do conhecimento e a defesa de um currículo que ressalte a experiência concreta dos sujeitos como situações significativas de aprendizagem. (P. 260)

Resulta daí, segundo a autora, que a referida pedagogia tende a assentar-se, de um lado, sobre o construtivismo, priorizando a dimensão subjetiva da aquisição dos conhecimentos e, de outro, sobre a articulação interdisciplinar, conferindo pouca atenção às dimensões social e histórica do processo educativo.

Ramos assume posição crítica em relação à proposta de interdisciplinaridade pelo fato de que, na forma proposta, esta se presta à desvalorização dos saberes escolares organizados em torno das disciplinas e à seleção instrumental dos conteúdos a serem ensinados, secundarizando o olhar reflexivo sobre estes, que permitiria, como diz a autora,

compreender o processo sócio-histórico de construção do conhecimento científico, possibilitando-o fazer uma leitura crítica do mundo, estabelecer 
relações entre fatos, idéias e ideologias, realizar atos ou ações (...) de forma crítica e criativa, compreender e construir ativamente novas relações sociais. (P. 154)

Por outro lado, torna-se necessário discutir um pouco mais essa perspectiva. Em primeiro lugar, porque a consecução da meta destacada na citação acima ultrapassa os campos disciplinares. É uma expectativa ampla, que envolve todo o conjunto das atividades escolares e o ultrapassa também. Vale lembrar, nesse sentido, que muitas propostas de ensino consideradas progressistas em outros momentos (p. ex., os Ginásios Vocacionais, na década de 1960) valeram-se da interdisciplinaridade para "realizar estudos do meio", que visavam exatamente esse mesmo objetivo amplo, sendo considerados muito bem sucedidos.

Em segundo lugar, porque os estudos sobre a história das disciplinas escolares têm demonstrado que a constituição destas, sua inclusão ou exclusão dos currículos e os conteúdos que privilegiam têm a ver, apenas em parte, com os conteúdos próprios das áreas científicas a que se vinculam, conforme, aliás, reconhecido no próprio texto, com base em Chevallard. Em outros termos, ainda que as disciplinas escolares tomem por base os conhecimentos produzidos nas diferentes áreas científicas, elas não são a expressão desses conteúdos.

Finalmente, cabe pensar sob outro aspecto a interdisciplinaridade em termos do ensino médio e da educação profissional de nível técnico. Para além da crítica correta à apropriação realizada pela pedagogia da competência, deve-se considerar que na escola média existem melhores possibilidades de desenvolvimento de um ensino interdisciplinar mais consistente do que nos graus inferiores de ensino. Pensando com Gramsci, parece-me que a interdisciplinaridade poderia contribuir para o desenvolvimento da escola criativa, para além de ativa, exatamente porque nesse nível os alunos já seriam detentores (ainda na perspectiva gramsciana) de um conjunto de saberes organizados que lhes permitiria, sob orientação, reconstruir os conhecimentos socialmente produzidos. Todavia, não se pode esquecer que a proposição gramsciana para esse nível de ensino pressupunha uma escola anterior a ele, muito diversa daquela que constitui, hoje, o nosso ensino fundamental.

Aparentemente, o caminho percorrido fornece a resposta à pergunta anteriormente apresentada: a "pedagogia das competên- 
cias", da forma como proposta e com os objetivos que colima, tem mais a ver com os interesses da produção do que com a autonomização dos alunos a ela submetidos, não obstante os discursos que sugerem ser ela um dos caminhos pelos quais tais alunos desenvolveriam não apenas os atributos necessários à sua condição de futuros trabalhadores, mas também aqueles que contribuiriam para que viessem a se tornar cidadãos. Esta é uma conclusão que provavelmente suscitará polêmicas, o que, para além das excelentes qualidades do livro, já o recomenda.

Referências bibliográficas

MACHADO, L.R.S. Qualificação do trabalho e relações sociais. In: FidAlGo, F.S. (Org.). Gestão do trabalho e formação do trabalhador. Belo Horizonte: Movimento de Cultura Marxista, 1996, p. 13-40.

NAVILLE, P. Essai sur la qualification du travail. Paris: Rivière, 1956.

SCHWARTZ, Y. De la "qualification" à la "compétence". Education Permanente, n. 123, p. 125-138, 1995.

TARTUCE, G.L. O que há de novo no debate da "qualificação do trabalho"? Reflexões sobre o conceito com base nas obras de Georges Friedmann e Pierre Naville. 2002. Dissertação (mestrado) - Programa de Pós-Graduação em Sociologia. Faculdade de Filosofia, Letras e Ciências Humanas da Universidade de São Paulo.

VILLAVICENCIO, D. Por una definición de la calificación de los trabajadores. In: IV CONGRESO ESPAÑOL DE SOCIOLOGIA: SOCIOLOGIA ENTRE DOS MUNDOS. Madrid, set. 1992. (Mimeo). 